\title{
Inferring Population Continuity Versus Replacement with aDNA: A Cautionary Tale from the Aleutian Islands
}

Author(s): Silvia E. Smith, M. Geoffrey Hayes, Graciela S. Cabana, Chad Huff, Joan

Brenner Coltrain, and Dennis H. O'Rourke

Source: Human Biology, 81(4):407-426.

Published By: Wayne State University Press

DOI: http://dx.doi.org/10.3378/027.081.0402

URL: http://www.bioone.org/doi/full/10.3378/027.081.0402

BioOne (www.bioone.org) is a nonprofit, online aggregation of core research in the biological, ecological, and environmental sciences. BioOne provides a sustainable online platform for over 170 journals and books published by nonprofit societies, associations, museums, institutions, and presses.

Your use of this PDF, the BioOne Web site, and all posted and associated content indicates your acceptance of BioOne's Terms of Use, available at www.bioone.org/page/terms_of_use.

Usage of BioOne content is strictly limited to personal, educational, and non-commercial use. Commercial inquiries or rights and permissions requests should be directed to the individual publisher as copyright holder. 


\title{
Inferring Population Continuity Versus Replacement with aDNA: A Cautionary Tale from the Aleutian Islands
}

\author{
SILVIA E. SMITH, ${ }^{1}$ M. GEOFFREY HAYES, ${ }^{2}$ GRACIELA S. CABANA ${ }^{3}$ CHAD HUFF, ${ }^{4}$ JOAN \\ BRENNER COLTRAIN, ${ }^{1}$ AND DENNIS H. O'ROURKE ${ }^{1}$
}

\begin{abstract}
In The Aleutian and Commander Islands and Their Inhabitants (Philadelphia: Wistar Institute of Anatomy and Biology, 1945), Hrdlička proposed a population replacement event in the Aleutian Islands approximately 1,000 years ago based on a perceived temporal shift in cranial morphology. However, the archaeological record indicates cultural, and presumed population, continuity for more than 4,000 years. We use mtDNA haplogroup data in the series of prehistoric eastern Aleutian samples $(n=86)$ studied craniometrically by Hrdlička to test alternative hypotheses regarding population continuity or replacement in the region. This molecular characterization, in conjunction with direct dating of individual specimens, provided increased resolution for hypothesis testing. Results indicate an apparent shift in mtDNA haplogroup frequencies in the eastern Aleutians approximately 1,000 years ago, in concert with changes in mortuary practices and isotopic signatures reflecting resource acquisition strategies. The earliest Aleut populations were characterized by a high frequency of haplogroup A, as are most modern populations of the North American arctic. Later prehistoric peoples in the Aleutians were characterized by a high frequency of haplogroup D and a correspondingly lower frequency of haplogroup $\mathrm{A}$, a pattern typified by modern Aleut populations.
\end{abstract}

Ancient DNA analyses allow us to examine variation in the genomes of ancient individuals and to make inferences about the prehistoric populations to which these individuals belonged. Unlike modern genetic studies, where sources of genetic information (i.e., saliva or blood or both) are easily accessible and abundant, skeletal remains are scarce and irreplaceable and contain only small amounts of degraded DNA. Researchers interested in testing hypotheses about past human

\footnotetext{
${ }^{1}$ Department of Anthropology, University of Utah, 270 S. 1400 E., Rm. 102, Salt Lake City, UT 84112.

${ }^{2}$ Division of Endocrinology, Metabolism, and Molecular Medicine, Department of Medicine, Feinberg School of Medicine, Northwestern University, Chicago, IL 60611; Department of Anthropology, Northwestern University, Evanston, IL 60208; and Center for Genetic Medicine, Northwestern University, Chicago, IL 60611.

${ }^{3}$ Department of Anthropology, University of Tennessee, Knoxville, TN 37996-0720.

${ }^{4}$ Department of Human Genetics, Eccles Institute of Human Genetics, 15 N 2030 E, Rm. 2100, University of Utah School of Medicine, Salt Lake City, UT 84112.
}

Human Biology, August 2009, v. 81, no. 4, pp. 407-426.

Copyright (C) 2009 Wayne State University Press, Detroit, Michigan 48201-1309

KEY WORDS: ANCIENT DNA, MTDNA HAPLOGROUPS, REPLACEMENT, POPULATION CONTINUITY, ALEUTIAN ISLANDS. 


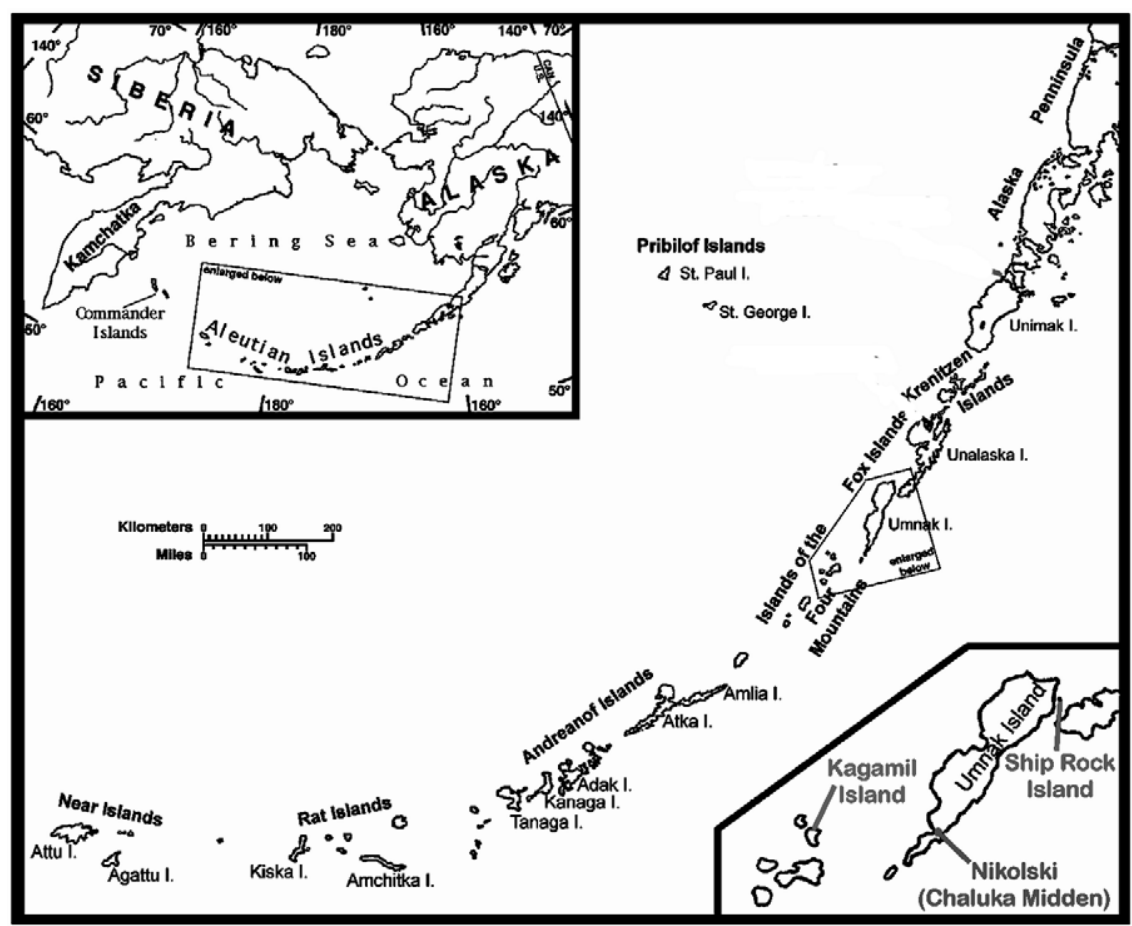

Figure 1. Sample locations in the eastern Aleutian Islands. Adapted from maps in Fitzhugh and Chaussonnet (1994), Keenleyside (1994), The International Atlas (1977), and Hayes (2002).

population histories, such as migration or colonization events, often have a limited number of samples available for molecular (destructive) analyses because of a variety of taphonomic processes. We obtained 86 ancient Aleut samples to test a hypothesized population replacement event in the Aleutian archipelago posited by Hrdlička (1945) and to assess the degree of similarity between ancient and modern Aleut populations.

\section{Background}

The Aleutian Islands are a volcanic chain extending westward from the Alaska peninsula that separates the Bering Sea to the north from the Pacific Ocean to the south (Figure 1). The island chain was first occupied by at least $8700 \mathrm{BP}$ (Laughlin et al. 1979), and the oldest skeletal remains, recovered from the Chaluka village midden on Umnak Island, date to approximately 4000 BP (Turner 1974). The earliest radiocarbon dates are recorded in the eastern portion of the chain, primarily at Umnak Island [Anangula, $8425 \pm 275$ BP (Laughlin 1963; McCartney and Turner 1966); Sandy Beach Bay, $8045 \pm 390$ BP (Aigner et al. 
1976); and Chaluka Village, $4028 \pm 100 \mathrm{BP}$ (Aigner 1978)], which represented the western terminus of the Alaska peninsula at glacial maximum. The earliest radiocarbon dates in the western islands are more recent [Buldir Island, $2347 \pm$ 84 BP (West et al. 1997); Shemya Island, $3540 \pm 60$ BP (Seigel-Causey et al. 1995); Attu Island, $2210 \pm 60 \mathrm{BP}$ (Lefèvre et al. 2001)]. Therefore, based on this east-west temporal distribution of radiocarbon dates, the consensus among North American archaeologists is that the Aleutians were colonized from the Alaskan mainland relatively quickly (Dumond 1987; Hrdlička, 1945; Laughlin 1980; McCartney 1984; cf. Black 1983, 1984).

The prehistory of the Aleutians is characterized by a striking continuity in cultural sequences from $4000 \mathrm{BP}$ onward and by an equally striking discontinuity in the morphological characteristics of the inhabitants (McCartney 1984). Hrdlička's (1945) classic examination of human skeletal remains from the Aleutians revealed the presence of two distinct cranial groups: one displaying a highvaulted, longer dolichocranic form and the other displaying a low-vaulted, rounder brachycranic form similar to that observed in contemporary inhabitants of the eastern portion of the chain. Hrdlička (1945) called these two groups pre-Aleut and Aleut, respectively, and hypothesized that a late migration (ca. AD 1000) of brachycranic Aleuts from the Alaskan mainland displaced or incorporated the dolicocranic pre-Aleuts already present. Unfortunately, he sorted the crania based on morphology, disregarding the stratigraphic position or geographic location from which they originated.

Modern Aleuts of the western and central islands are indeed dolicocephalic, whereas brachycephaly characterizes Aleut groups of the eastern islands in the chain (Laughlin and Marsh 1951). In the absence of morphometric differences other than cranial shape and lacking spatiotemporal evidence for a population intrusion, Laughlin and Marsh (1951) renamed Hrdlička's pre-Aleut and Aleut groupings as Paleo-Aleut and Neo-Aleut, respectively (the terms most commonly encountered in the literature and the terminology we adopt here), and proposed that the differences between the groups were not sufficient to warrant a population replacement explanation. Instead, after the initial migration of Paleo-Aleuts into the island chain, three breeding isolates (west, central, and east) were maintained by large geographic distance and dialect boundaries (Laughlin 1975, 1980; Laughlin and Aigner 1975). Laughlin argued that population size in the eastern Aleutians (about 10,000) was sufficiently large for selection on cranial shape to counter the effects of drift, altering the Paleo-Aleut long-headedness into the NeoAleut round-headedness. Conversely, smaller population sizes in the central and western islands (about 5,000 and about 1,000, respectively) permitted genetic drift, not natural selection, to become the primary evolutionary force influencing cranial morphology. According to this scenario, the Paleo-Aleut characteristic of dolicocephaly was maintained in central and western Aleut populations until the present (Laughlin 1980; Laughlin and Marsh 1951). Although both Laughlin and Marsh (1951) and Hrdlička (1945) recognized a temporal change in cranial form in the prehistoric eastern Aleutians, they differed in their inference of the 
mechanism responsible for the change. Hrdlička hypothesized a migration/replacement event, whereas Laughlin and Marsh considered the temporal shift in cranial form to be the result of in situ evolutionary change.

In previous tests of these alternative hypotheses, Turner's $(1967,1991)$ analysis of nonmetric dental traits detected no significant differences between the Paleo-Aleut and Neo-Aleut dentitions. He identified dental differences between prehistoric eastern and western populations, which also exist among contemporary eastern and western populations (Moorrees 1957), indicating some time depth to the geographic distribution of these dental characteristics (Turner 1974). Following Laughlin, Turner (1974) suggested a strong role for genetic drift in the west, an increased population size in the east, and gene flow smoothing trait frequencies into the current east-west clinal distribution. Linguistic analyses can be used to support either the replacement or continuity hypothesis. A hypothesis of population continuity, with long periods of isolation between the three regions (east, central, and west), predicts that a single language would diversify into the three observed Aleut dialects. However, Woodbury (1984) noted a uniformity of the dialects and therefore advocated a recent migration across the islands (Woodbury 1984).

Although linguistic, archaeological, and morphological data sets have all contributed to our understanding of Aleut prehistory, the determination of the number and antiquity of migrations into the island chain remains unresolved. Analysis of molecular genetic markers permits identification of the genetic relationships between prehistoric and contemporary Aleut populations and provides an evolutionary perspective from which to infer population histories and migrations (Shields et al. 1993). Through the use of ancient DNA (aDNA) data, replacement versus continuity models can be directly tested by comparing the patterns of genetic variation in pre- and posttransition populations. This approach has been applied to similar problems in other archaeological contexts [e.g., the Neanderthal/anatomically modern humans transition (Krings et al. 1997); the Numic expansion into the Great Basin (Kaestle and Smith 2001; O'Rourke et al. 1999; Parr et al. 1996); and the Dorset/Thule transition in the eastern Canadian arctic (Gilbert et al. 2008; Hayes 2002; Hayes et al. 2003, 2005)].

To address the general issue of whether the prehistory of the Aleutian Islands is characterized by population continuity or a major migration/replacement event, as proposed by Hrdlička, we characterized mtDNA haplogroup status in the same individuals studied by Hrdlička (1945) and from which he deduced a population replacement (Table 1). We tested for significant differences in mtDNA haplogroup frequencies between the following pairs of groups: (1) two cranially distinct groups, Paleo-Aleuts and Neo-Aleuts (i.e., Hrdlička's pre-Aleuts and Aleuts); (2) the Paleo-Aleut cranial group compared to the modern Aleut sample; (3) all ancient samples, regardless of cranial shape or age, compared to the modern Aleut sample; and (4) all ancient samples, predating AD 1000, regardless of cranial shape, versus all samples (ancient and modern) postdating $\mathrm{AD}$ 1000, regardless of cranial shape. For completeness, we also evaluated Hrdlička's Neo-Aleut group against the modern genetic sample and tested for heterogeneity 
Table 1. Number and Provenance of Paleo-Aleut and Neo-Aleut Samples Analyzed with Known Mitochondrial Haplogroup

\begin{tabular}{lccccccc} 
& \multicolumn{3}{c}{ Hayes (2002), $N=30$} & & \multicolumn{3}{c}{ Smith (2005), $N=39$} \\
\cline { 2 - 3 } Site & 0 & 6 & 1 & & 2 & 12 & 2 \\
\hline Kagamileo-Aleut & Neo-Aleut & Unknown & & Paleo-Aleut & Neo-Aleut & Unknown \\
Shiprock Island & 5 & 4 & 1 & & 5 & 0 & 2 \\
Chaluka Midden & 11 & 2 & 0 & & 15 & 0 & 1 \\
\hline
\end{tabular}

across archaeological sites. The aDNA data reported here were collected as part of a collaborative project to evaluate genetic variation across time and space in the Aleutian archipelago. The contemporary mtDNA haplogroup frequency data derive from a parallel research project that examined patterns of genetic variation among contemporary Aleut populations residing on the islands and on the mainland (Rubicz et al. 2003; Zlojutro et al. 2006).

\section{Methods}

Mitochondrial DNA (mtDNA) is a useful tool for characterizing genetic variation in ancient populations because of the increased probability of successful extraction and amplification of the organelle's multicopy genome. We analyzed genetic variation in the form of a 9-bp deletion and five enzyme restriction sites that are known to be polymorphic and informative in most indigenous North American populations and that collectively help to define four primary Native American haplogroups, A, B, C, and D (e.g., Bandelt et al. 2003; Tamm et al 2007; Torroni et al. 1993) (Table 2). The restriction sites screened at np 10394 (AluI) and np 10397 (DdeI) do not define any of the mtDNA haplogroups under study. However, they are present in haplogroups $\mathrm{C}$ and $\mathrm{D}$, which are defined by the absence of diagnostic restriction sites. In aDNA samples, failure to identify restriction sites by restriction enzymes may occur for a variety of reasons other than absence of the restriction site. Thus inclusion of these two additional markers provides additional confirmation of haplogroup diagnosis and authenticity in these data. We did not examine markers that define the rarer fifth founding haplogroup, X2a (Brown et al. 1998; Smith et al. 1999), as it has never been observed among arctic and western subarctic North American populations and none of the ancient Aleut samples resulted in ambiguous marker distributions that would have suggested the presence of any unobserved haplogroups.

Given the comparatively large number of samples available, we took a twostage approach to the analysis. The first stage consisted of typing a randomly selected subset of 36 individuals by screening for all four diagnostic haplogroups (Hayes 2002). Because only two (A and D) of the four possible haplogroups were observed in the first stage (see Results section) and because the same two haplogroups were the only haplogroups observed among living Aleuts (Rubicz et al. 
412 / SMITH ET AL.

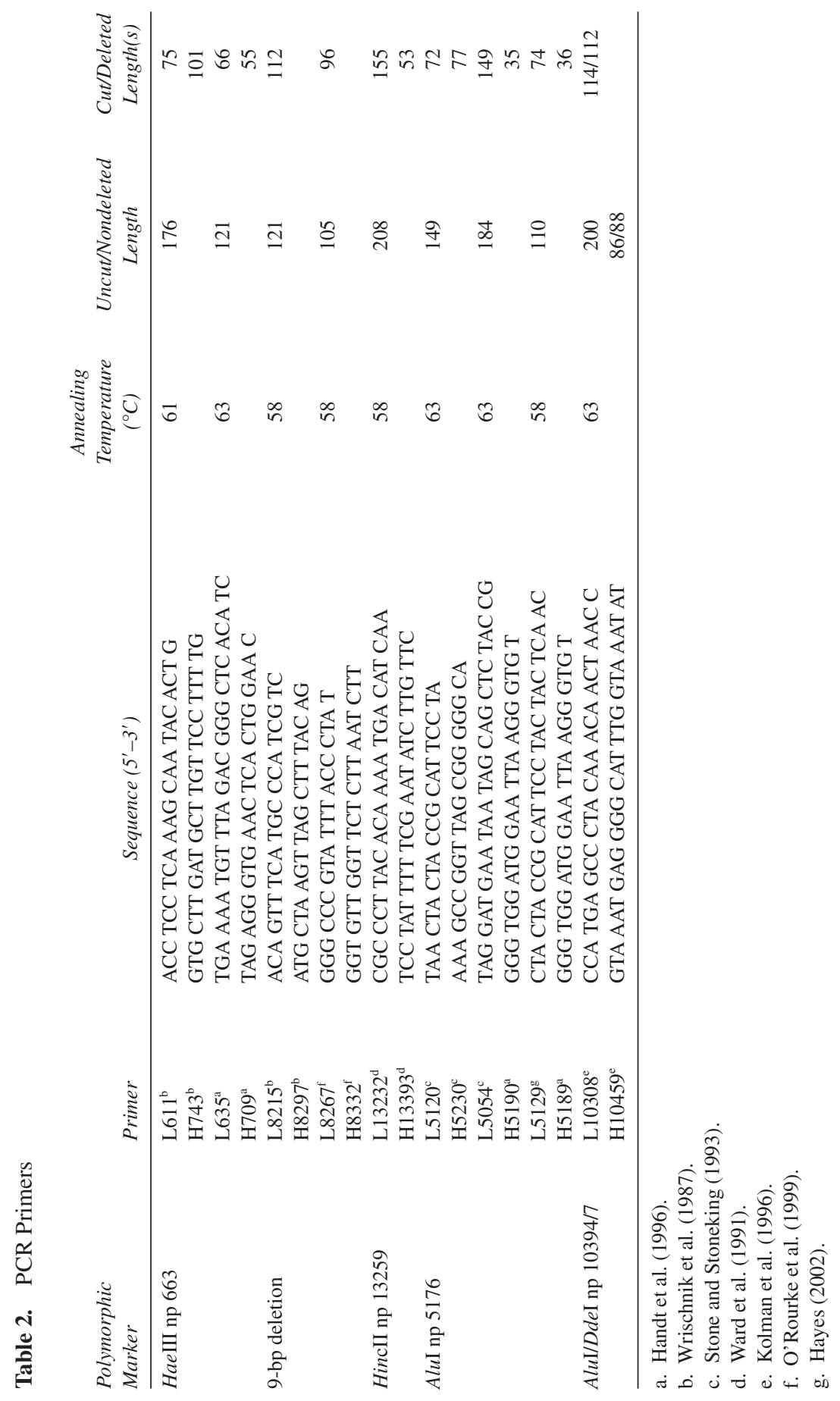


2003; Zlojutro et al. 2006), the second stage consisted of typing only the HaeIII 663 and AluI 5176 restriction sites (defining markers for haplogroups A and D) in the additional 50 individuals (Smith 2005). None of the samples analyzed during the second stage that yielded amplifiable DNA showed evidence of membership in haplogroups other than A or D (see Results section).

Sample Provenance. Rib samples from prehistoric Aleut burials were collected from the National Museum of Natural History (NMNH), Washington, D.C. The Aleut physical anthropology collection at NMNH consists primarily of burials collected by Hrdlička and his students from 1936 to 1938. The remains of 59 Paleo-Aleuts and six Neo-Aleuts were excavated from the Chaluka midden outside Nikolski village, Umnak Island. These Paleo-Aleut burials are the earliest human skeletal remains recovered from a clear context in Alaska (Oswalt 1967), with the earliest burials in the midden dating to nearly 4000 BP (Turner 1974). The Neo-Aleut burials were considered intrusive and believed to be post-Russian contact (Hrdlička 1945). From two caves on Ship Rock Island, Hrdlička removed the remains of 62 individuals. The time span of this burial area is unknown, but artifact association suggests early postcontact for at least some of the individuals (Hrdlička 1945). According to Turner (1991), the burial caves were most likely used by Aleuts of eastern Umnak Island. Hrdlička also recovered 234 skeletal remains from two Kagamil Island caves. Mask fragments found among the burials date between 900 and 1100 BP (T. Bank, personal communication to Lydia Black, cited in Black 1983). The caves were most likely still in use into the postcontact period (Laughlin 1992, cited in Keenleyside 1994; Laughlin 1980).

Fragmentary rib samples from 86 individuals were removed from the NMNH collection, placed in sealed zipper bags, weighed, and labeled (see Table 1). The collector (M. G. Hayes) wore a lab coat, disposable oversleeves, and a mask at all times during the collection process, and he changed sterile latex gloves between each individual sample collection to reduce the risk of surface contamination of the samples, although it is likely that museum curators and past researchers did not use precautions to avoid contamination.

DNA Extraction and Purification. A quarter to half a gram of bone was surface-decontaminated with a 15 -min bleach treatment, rinsed three times using DNA- and RNA-free $\mathrm{H}_{2} \mathrm{O}$, and then decalcified for $72 \mathrm{hr}$ in $10 \mathrm{ml}$ of $0.5 \mathrm{M}$ EDTA ( $\mathrm{pH}$ 8.5). Proteins were digested overnight at $56^{\circ} \mathrm{C}$ in $1.5-2.0 \mathrm{ml}$ of $\mathrm{PK}$ buffer [50 mM Tris (pH 8.0), $1 \mathrm{mM} \mathrm{CaCl}_{2}, 1 \mathrm{mM}$ DTT, $0.5 \%$ tween $20,1 \mathrm{mg} / \mathrm{ml} \mathrm{PK}$, or, alternatively, $50 \mathrm{mM}$ Tris- $\mathrm{HCl}$ (pH 8.0), $450 \mathrm{mM}$ EDTA (pH 8.5), 0.5\% tween 20, $1 \mathrm{mg} / \mathrm{ml}$ PK]. The digested product was subsequently cleaned with either Qiagen QIAquick silica-gel spin column concentration, following the method of Yang et al. (1998), or phenol-chloroform extraction, following the method of Parr et al. (1996). If phenol-chloroform extraction was performed, the resultant extracts, eluted in $35 \mu \mathrm{l}$ TE buffer, often required 1:5 and 1:10 dilutions to reduce the concentration of PCR inhibitors (Hummel et al. 1992). 
Table 3. Haplogroup Distributions

\begin{tabular}{lcccc} 
& $N$ & Haplogroup A & Haplogroup D & No Data \\
\hline Stage 1 (Hayes 2002) & & & & \\
$\quad$ Paleo-Aleut & 19 & $4(25 \%)$ & $12(75 \%)$ & 3 \\
$\quad$ Neo-Aleut & 15 & $4(33 \%)$ & $8(67 \%)$ & 3 \\
$\quad 34$ & 8 & 20 & 6 \\
$\quad$ Total (2 samples of uncertain origin) & & & & \\
Stage 2 (Smith 2005) & 27 & $12(55 \%)$ & $10(45 \%)$ & 5 \\
$\quad$ Paleo-Aleut & 18 & $4(33 \%)$ & $8(67 \%)$ & 6 \\
$\quad$ Neo-Aleut & 45 & 16 & 18 & 11 \\
$\quad$ Total (5 samples of uncertain origin) & & & & \\
Combined data sets & 46 & $16(42 \%)$ & $22(58 \%)$ & 8 \\
$\quad$ Paleo-Aleuts & 33 & $8(33 \%)$ & $16(67 \%)$ & 9 \\
$\quad$ Neo-Aleuts & 79 & 24 & 38 & 17 \\
$\quad$ Total & & & & \\
Combined data sets & 15 & $8(72 \%)$ & $3(28 \%)$ & 4 \\
$\quad$ Pre AD 1000 & 64 & $12(23 \%)$ & $40(77 \%)$ & 12 \\
$\quad$ Post AD 1000 & 79 & 20 & 43 & 0 \\
$\quad$ Total & 198 & $58(28 \%)$ & $142(72 \%)$ & \\
Living Aleuts & & & & \\
\hline
\end{tabular}

Polymerase Chain Reaction. Reactions were set up at $4^{\circ} \mathrm{C}$ in $25-\mu 1$ or $50-\mu 1$ volumes [1× Deep Vent reaction buffer (New England Biolabs, Ipswich, Massachusetts), $1 \times$ nonacetylated BSA (New England Biolabs), $200 \mathrm{mM}$ of each dNTP (Strategene, Cedar Creek, Texas), 0.0-2.0 mM MgSO ${ }_{4}$ (New England Biolabs), $0.15-0.25 \mu \mathrm{m}$ of each primer (Oligos Etc., Wilsonville, Oregon), 0.7-2.0 units of Deep Vent (exo-) polymerase (New England Biolabs), 3-5 $\mu \mathrm{l}$ aDNA sample]. Primer sequences are given in Table 2. Reactions were hot started (Chou et al. 1992) at $95^{\circ} \mathrm{C}$ for $5 \mathrm{~min}$ before the first amplification cycle and were extended at $72^{\circ} \mathrm{C}$ for $5 \mathrm{~min}$ after the final cycle. Cycle parameters included $35 \mathrm{~s}$ at $95^{\circ} \mathrm{C}$ denaturation, $1 \mathrm{~min}$ at the appropriate annealing temperature (see Table 3), and 15 $\mathrm{s}$ at $72^{\circ} \mathrm{C}$ extension through 40 cycles in a Perkin Elmer 480 thermal cycler. The PCR product (10-12 $\mu \mathrm{l})$ was resolved on 3-4\% 3:1 NuSieve gels, adjacent to a size standard (MspI digested pBR322).

Restriction Enzyme Digestion. For PCRs yielding an appropriately sized amplification product, the remaining 13-15 $\mu \mathrm{l}$ of PCR product was restrictiondigested overnight at $37^{\circ} \mathrm{C}$ according to the manufacturer's (New England Biolabs) recommendations. Samples were cleaned with Pro-cipitate (Biotech Support Group, Monmouth Junction, New Jersey) before digestion to remove restriction enzyme inhibitors. Failure to do so may lead to incomplete digestions and hence a false-positive signal for contamination. The digestion products were again resolved on 3-4\% 3:1 NuSieve gels, adjacent to undigested samples to facilitate interpretation. 
Contamination and Quality Control. Contamination from modern nucleic acids is a constant risk when working with aDNA (e.g., Handt et al. 1994; Pääbo et al. 2004). Measures to both reduce the possibility of contamination and detect it when it does occur include the following: (1) Only bone samples without pathogenic lesions were chosen for extraction to reduce the risk of the interior of the bone samples having been contaminated during routine handling by prior investigators or museum personnel. (2) All samples were pretreated with bleach to remove surface contamination before aDNA extraction. (3) Protocols used ultraviolet (UV) cross-linked and aDNA dedicated instruments, labware, and aerosolresistant filtered pipette tips. Reagents were aliquoted into single-use volumes. (4) Pre- and post-PCR activities were performed in separate laboratories located at opposite ends of the building, each fully dedicated to aDNA analysis. Amplifications of modern DNA positive controls are never performed in this building. (5) Laboratory personnel wore masks, labcoats, oversleeves, and gloves. (6) Preamplification procedures were performed in a HEPA-filtered positively pressured sterile enclosure equipped with an internal UV light, housed in a HEPA-filtered positively pressured room. (7) The thermal cycler, located on a separate floor and in a separate wing of the building, was UV cross-linked before and after each PCR. (8) Two to four negative PCR controls and at least one negative extraction control were used to signal false-positives during each PCR. Evidence of amplification in any one of these negative controls was rare, and no data have been included for which any such evidence of contamination was present. (9) To further ensure the authenticity of the aDNA typings, we confirmed all results with individual marker amplifications from multiple independent extractions. All samples were replicated with marker amplifications from at least three independent extractions. No sample yielded evidence of persistent contamination such that it required elimination from the analyses. Any additional replicates were typically the result of failed amplification rather than positive evidence for contamination. (10) Finally, all laboratory personnel involved in this study are characterized by European, not Native American, mtDNA haplotypes. Thus they do not harbor any of the markers defining the haplogroups found in the ancient Aleut samples.

Radiocarbon Dating. Because the temporal context of the burials excavated by Hrdlička was not properly recorded and because the stratigraphy was at times disregarded (Laughlin and Marsh 1951), we radiocarbon-dated most samples. Full results of the radiocarbon dating are described elsewhere (Coltrain et al. 2006).

Analytical and Simulation Methods. We used three methods to evaluate each hypothesis in turn. Depending on whether sample sizes were small or large, we used either Fisher's exact or chi-square test within Statistica 8.0 (StatSoft Inc. 2008) to assess the degree of difference between two groups. These methods, however, cannot distinguish among alternative causes of difference, such as microevolutionary change. To take into account microevolutionary processes, we used Nsitu, a computer simulation model that uses paleodemographic data to 
simulate population dynamics over time, accounting for genetic drift, local gene flow, and fluctuations in population sizes. The model statistically tests the null hypothesis of in situ change (i.e., population continuity) between two population samples in the absence of external migration. Details of the model can be found in Cabana et al. (2008) and Cabana (2002).

Table 4 provides the values of the process parameters used in each of the Nsitu simulation runs. Calculation of the number of generations used in each run is based on the difference between the average date of the later sample minus that of the earlier sample. Because Nsitu allows the user to specify desired gene flow rates between two population groups, we ran simulations with two gene flow rates, $10 \%$ and $25 \%$. We also ran simulations with no gene flow to assess the effects of pure drift.

To provide guidance for effective size estimates to be used in the Nsitu simulations of prehistoric Aleut population dynamics, we estimated the $95 \%$ upper confidence limit for effective population size $\left(N_{e}\right)$ from forward in-time simulations based on the Fisher-Wright model. The test statistic was the absolute deviation in haplogroup frequencies between the two compared groups, and the upper confidence limit for $N_{e}$ was the largest population size that was consistent with the observed deviation in haplogroup frequencies. This limit was estimated with a binary search through population size, where a simulation of 10,000 iterations was executed for each population size in the search. If the deviation in haplogroup frequencies was less than the observed value in more than $95 \%$ of the iterations, then the population size was treated as a lower bound for the confidence limit; otherwise it was treated as an upper bound. The binary search was complete when the difference between the upper and the lower bound was 1 or less. The PaleoAleut samples were assumed to be a random subset of the ancestral population at the start of each iteration. Then, assuming a uniform prior condition, the ancestral haplogroup frequencies in each simulation were drawn at random from the posterior distribution using rejection sampling based on the binomial likelihood function and the observed Paleo-Aleut haplotypes. All simulations assumed a single randomly mating population of constant population size and a direct ancestor-descendant relationship between Paleo-Aleuts and Neo-Aleuts over 46 generations, which approximates the mean age difference between the two groups.

By using this simulation approach, we estimated that $N_{e}$ for ancient Aleuts did not exceed 220 individuals. Similar $N_{e}$ estimates from haplogroup frequency data have also been obtained by others using different methods (Marchani et al. 2007) and are consistent with ethnographic estimates from other arctic populations (e.g., Burch 1998). Accordingly, for the Nsitu simulations we used a mean $N_{e f}$ of 50 , with a range of $30-75$.

\section{Results}

All the samples processed for aDNA analyses had adequate carbon to nitrogen ratios for good bone collagen preservation (range 2.9-3.6) (Coltrain et al. 
Population Continuity Versus Replacement / 417

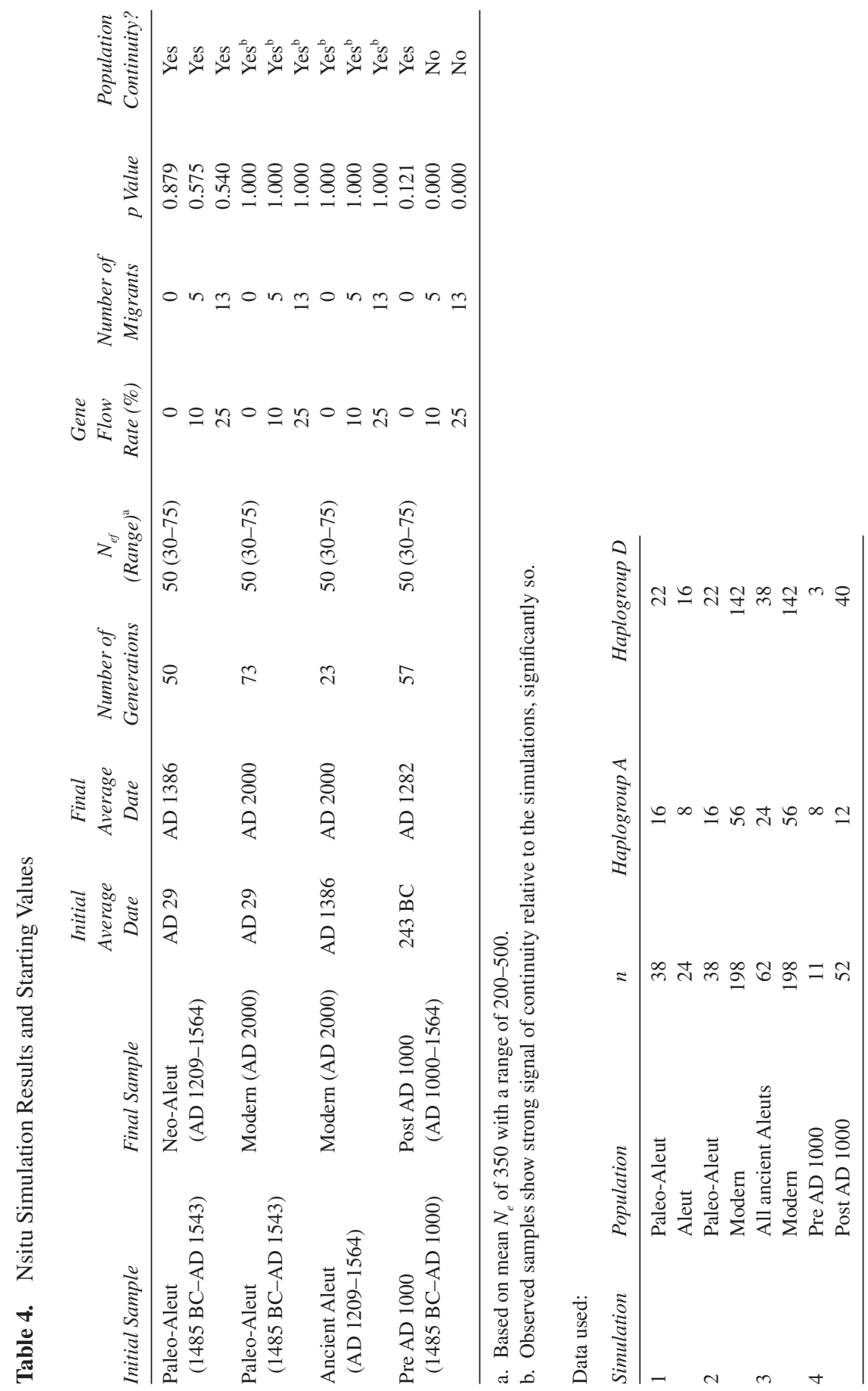


2006), suggesting a high likelihood of extracting DNA from bone. Stable isotope analyses indicated that the ancient Aleut individuals included in this study relied primarily on marine resources. More specifically, the burials from Chaluka had a mean $\delta^{13} \mathrm{C}$ value of $-12.3 \pm 0.5 \%$ o $(n=32)$; the burials from Kagamil Island had a mean of $-12.7 \pm 0.3 \% \circ(n=32)$; and the burials from Ship Rock had a mean of $-12.4 \pm 0.5 \%$ o $(n=16)$, indicating diets consistently high in marine resources (Coltrain et al. 2006). Statistically significant differences in dietary habits between Paleo- and Neo-Aleuts and between pre- and post-1000 BP individuals suggest that the two groups may have had divergent resource acquisition strategies (Coltrain et al. 2006).

Radiocarbon dating of 63 samples included in this study confirmed that all burials were pre-Russian contact (Figure 2). Burials older than $1000 \mathrm{BP}$ are uniformly Paleo-Aleut by Hrdlička's (1945) criteria $(n=15)$, whereas Neo-Aleut burials, which date after cal. 1000 BP, coexisted with Paleo-Aleuts, sensu Hrdlička (1945), until the time of Russian contact. Thus Paleo-Aleuts span a considerably longer time frame in the eastern Aleutians than do the putative Neo-Aleut migrants (Coltrain et al. 2006).

Genetic and Statistical Analyses. Mitochondrial DNA was successfully extracted from 69 of the 86 available samples (Hayes 2002; Smith 2005). This high success rate is likely due to the favorable interment conditions of the burials, which ranged from an alkaline midden to cold, dry caves. Although all samples were subjected to at least three independent extractions, with marker typing completed for each, only a single sample actually required analysis of the third extract to resolve haplogroup status. This was the result of an ambiguous signal in a restriction site in one of the extracts rather than positive evidence of contamination in any of the control samples. The haplogroup distribution from the samples analyzed in stage 1 are similar to those analyzed in stage 2 (see Table 3) but present some statistically significant differences (Table 5). The frequency of haplogroup A increased from $29 \%$ in stage 1 to $39 \%$ when the remaining samples were added. Conversely, haplogroup D frequencies decreased from $71 \%$ to $61 \%$. More important, the uniformity in haplogroup $\mathrm{A}$ and $\mathrm{D}$ frequencies in the ancient and modern samples based on the initial examination (Hayes 2002) (stage 1) is not replicated in the stage 2 analysis (Smith 2005), where haplogroup frequency differences between early and late prehistoric inhabitants of the eastern Aleutian region are apparent. The frequency of haplogroup A in individuals dating earlier than 1000 $\mathrm{BP}$ is 0.73 , compared to a frequency in individuals living after that date of 0.23 . Similarly, the frequency of haplogroup D, so common in modern Aleuts, is $77 \%$ in later prehistoric samples (after $1000 \mathrm{BP}$ ) but only $27 \%$ among the earliest eastern Aleut samples.

These results are corroborated in the Nsitu simulations. Most comparisons exhibit no statistical difference in haplogroup frequencies, with the exception of the pre- versus post-AD 1000 comparison of the full data set (see Table 4). In this case the continuity hypothesis is rejected if local groups were exchanging at least 


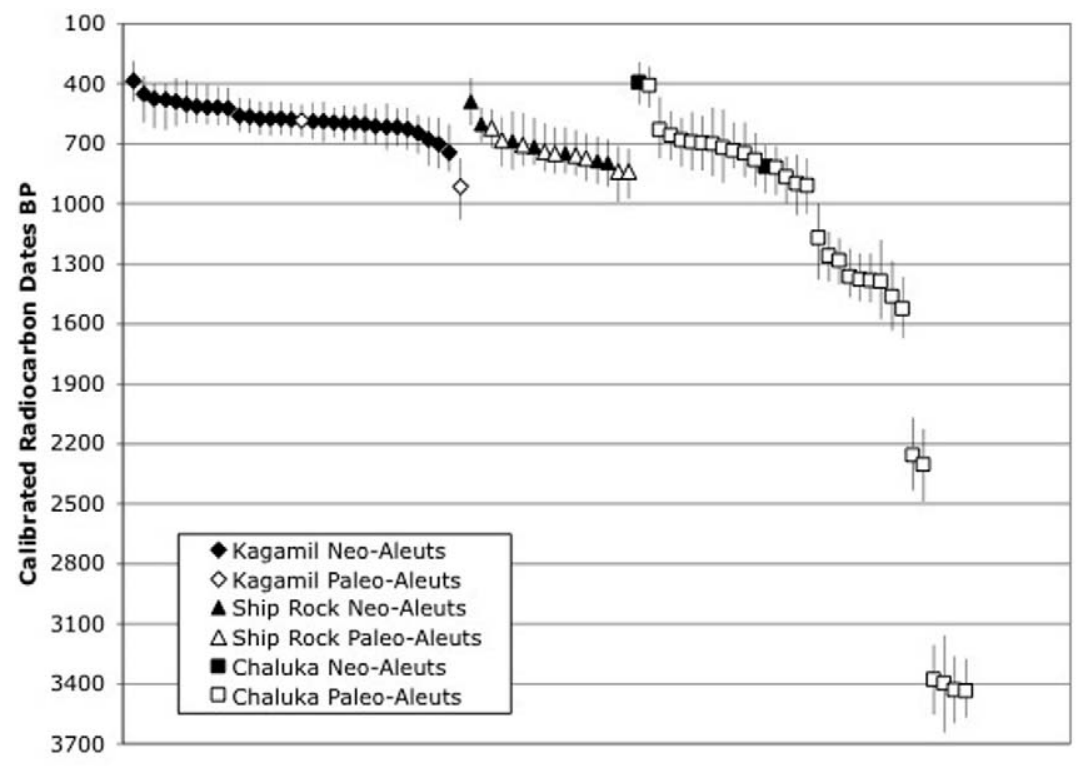

a

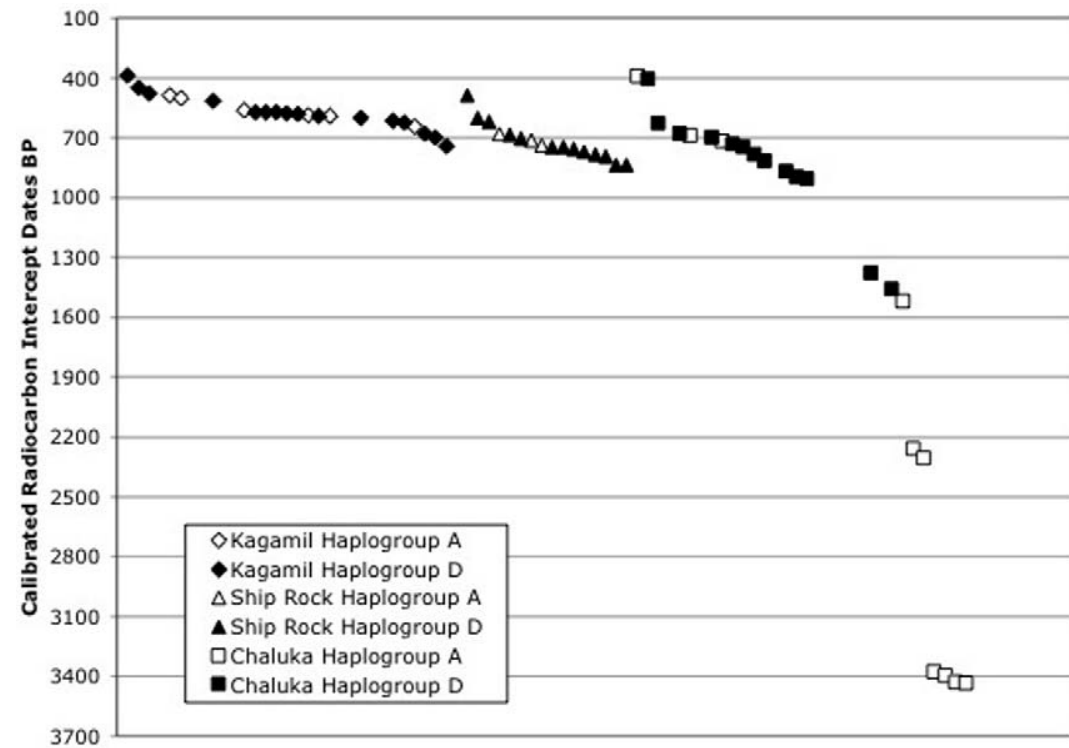

b

Figure 2. AMS (accelerator mass spectrometry) ${ }^{14} \mathrm{C}$ dates of samples analyzed. (a) Dates of samples by site and Hrdlička's cranial category. Vertical bars on sample symbols indicate 2 SD ranges for each AMS ${ }^{14} \mathrm{C}$ date. (b) Dates of samples by site and mtDNA haplogroup. The larger number of samples in part (a) reflects samples that were dated but for which no DNA was obtained. 
Table 5. Contingency Tests

\begin{tabular}{lcc} 
Comparison & Hayes (2002) P Value & $\begin{array}{c}\text { Smith (2005) }+ \\
\text { Hayes (2002) P Value }\end{array}$ \\
\hline Kagamil vs. Ship Rock vs. Chaluka & 0.308 & 0.039 \\
Paleo-Aleuts vs. Neo-Aleuts & 0.420 & 0.59 \\
Paleo-Aleuts vs. modern Aleuts & 0.44 & 0.1226 \\
Neo-Aleuts vs. modern Aleuts & 0.488 & 0.49 \\
All ancient Aleuts vs. modern Aleuts & 1 & 0.09 \\
Pre vs. post AD 1000 samples & 0.165 & 0.0028 \\
\hline
\end{tabular}

one migrant per generation. Interestingly, two comparisons (hypotheses 2 and 3) yielded $P$ values equal to 1 , indicating that these groups are more similar than expected, even with considerable local gene flow.

\section{Discussion}

This study was designed to refine our knowledge of Aleut population history with respect to colonization events in the archipelago and to linkages between prehistoric and modern Aleut populations. To address these questions, we collected and analyzed molecular markers from 86 prehistoric rib samples. We divided the study into two stages: The first 36 samples were analyzed by Hayes in 2002, and the remaining 50 samples were analyzed by Smith in 2005. Radiocarbon dating and stable isotope analyses (Coltrain et al. 2006) took place following the first stage of DNA analyses, such that the age of each sample was unknown during the first stage of molecular genetic analysis.

A comparison of mitochondrial haplogroup distribution from stage 1 data to that of the combined data (i.e., $n=69$ DNA samples) reveals similar patterns but also statistically significant differences. The similarity is reflected in the lack of statistical difference in haplogroup frequencies of Paleo- and Neo-Aleut samples in either data set. Although it was not known at the outset of the project, we subsequently demonstrated that Neo-Aleuts appear only after AD 1000. All individuals dating before that period are Paleo-Aleut (Coltrain et al. 2006). After AD 1000, Paleo- and Neo-Aleut morphological groups overlap in time through early Russian contact. However, by increasing the genetic sample size from 30 to 69 individuals, we detect a temporal change in haplogroup frequency across the $\mathrm{AD}$ 1000 rubicon, a difference not seen when comparing samples pre- and postdating other time intervals.

For either stage 1 or stage 2 data, no statistically significant differences in haplogroup frequencies between Paleo- and Neo-Aleuts were observed (see Table 5). This is not surprising now that we know that both groups coexisted in the Aleutians from approximately 1000 BP until Russian contact in the mid-18th century. However, when the sample size increased to the full sample of 69 genetically 
characterized individuals, Fisher's exact test revealed a statistically significant difference in haplogroup frequencies between individuals pre- and postdating $\mathrm{AD}$ 1000, the date postulated by Hrdlička to have marked the population replacement event. Likewise, with the larger sample size, the chi-square test shows a significant difference of haplogroup distribution by site (Kagamil, Umnak, and Ship Rock Islands; Table 5).

Sampling strategies have certainly contributed to the disparity in results, because the age of each sample was unknown until after the stage 1 analysis was completed. By chance, the initial samples selected for analysis all came from the most recent prehistoric time period. None of the randomly selected samples analyzed in stage 1 dated to older than 1000 BP. Thus the initial inference of no observable temporal trends in haplogroup frequency in ancient Aleut populations (Hayes 2002) was based on a restricted time frame and is a conclusion that can no longer be sustained given the expanded sample set and temporal scale.

Ward et al. (1991) suggested that a sample size of approximately 30 individuals was sufficient to detect about $75 \%$ of mtDNA lineages in a population if they existed at polymorphic frequencies. This is likely true for real biological populations but is clearly not the case here, where ancient samples come, at best, from a continuous population (or populations) that existed over time. An mtDNA sample size of 30 was not sufficient to detect changes in ancient Aleut genetic history. Comparable sample sizes are probably insufficient to infer population dynamics in most such cases, especially when most samples used in aDNA analyses are not directly dated. Doubling the number of samples for our analysis effected a substantial change in our inferences regarding population change and stability in Aleut prehistory. Although increased sample sizes are clearly important in aDNA studies that use frequency data to infer historical population dynamics, it is crucially important to directly date each specimen that is examined genetically. Without this level of temporal resolution for ancient samples, any evolutionary hypotheses or population history reconstructions are effectively baseless. In the present study, neither the contemporaneity of Paleo- and Neo-Aleut samples nor the temporal change in mtDNA haplogroup frequencies could have been observed without direct dating of each sample.

Haplogroup frequencies from the full Aleutian data set suggest that there is a difference between individuals before and after AD 1000, the time suggested by Hrdlička to have delimited a population replacement event. As noted, stable isotope analyses support this difference and suggest potential additional disparities between Paleo- and Neo-Aleut groups (Coltrain et al. 2006). However, the observed temporal shift in haplogroups A and D is based on only 11 samples that predate $1000 \mathrm{BP}$. This is a small sample on which to base an inference of frequency change, but it is perhaps relevant that the only individuals who possess haplogroup D in this older series are three of the four youngest. The seven oldest samples (all predating $1200 \mathrm{BP}$ ) are monomorphic for haplogroup A. Nevertheless, taken as a whole, mitochondrial haplogroup frequencies of the full series 
of ancient Aleuts examined here, irrespective of age or cranial morphology, resemble those of modern Aleuts (Rubicz et al. 2003; Zlojutro et al. 2006). We detect a difference only between ancient and modern Aleuts if we account for the documented temporal change in mtDNA haplogroup frequencies among prehistoric eastern Aleuts. Thus late prehistoric Aleut populations (both Paleo- and NeoAleuts postdating $1000 \mathrm{BP}$ ) are genetically indistinguishable from contemporary Aleut populations. Alternatively, early Paleo-Aleuts (predating $1000 \mathrm{BP}$ ) appear to be maternally genetically distinct from both later prehistoric populations and contemporary Aleut communities and seem unlikely to have given rise to these later populations solely through population growth and genetic drift. It is of interest that in modern arctic populations of North America, mtDNA haplogroup A is fixed in some populations and occurs at high frequency in all others. Haplogroup $\mathrm{D}$, if present, is at low frequency in these populations (Helgason et al. 2006; Saillard et al. 2000). Thus, in contrast to late prehistoric and modern Aleut communities, the earliest Aleuts appear to be more similar to other populations farther north in the American arctic. Whether this result suggests a common ancestry between early Aleuts and Inupiat populations of the high arctic must await additional sequence analysis of early samples across the arctic.

The unexpected significant similarity between Paleo-Aleuts (and the full ancient series) and the modern sample observed in the Nsitu simulations deserves comment. Recall that most of the Paleo-Aleut samples were contemporaneous in time with Neo-Aleuts and are mitochondrially indistinguishable from them. As such, both groups in the late prehistoric appear directly ancestral to modern Aleuts, so considerable similarity is not unexpected. The similarity may also simply reflect the vagaries of sampling the prehistoric record for genetic analysis and the fact that the current analysis is based on frequency data from only two haplogroups that exist in both the ancient and the modern populations of Aleuts.

These data are not sufficient to unequivocally document the population replacement event advocated by Hrdlička (1945), but coupled with changes in mortuary practices that appear to coincide with the observed mtDNA frequency changes, the data are consistent with a population transition in the region that had some effect on the distribution of maternal lineages in the Aleutians. Given the temporal overlap of the Paleo- and Neo-Aleut samples, it is clear that this transition is not adequately documented by cranial shape, as suggested by Hrdlička (1945). Whether the transitions observed in the mtDNA haplogroup data reflect a migration of new populations into the archipelago from the Alaska peninsula, a redistribution of existing populations resulting in significant local founder effects, or the effects of kin-structured migration between islands of the chain awaits further analysis of early populations in other parts of the archipelago. Resolving these alternative population history scenarios will undoubtedly require substantially larger sample sizes and greater genetic resolution from both mtDNA sequence data and assessment of patterns of genetic variation in autosomal markers, including those of the $\mathrm{Y}$ chromosome. 


\section{Conclusions}

This two-part study was designed to increase our understanding of ancient Aleut population dynamics and prehistory. Genetic analyses and simulations in conjunction with stable isotope and radiocarbon age determinations of bone fragments from a sample of 86 ancient Aleut individuals suggest that (1) there is a statistically significant difference in haplogroup frequencies among individuals who pre- and postdate AD 1000, the date postulated by Hrdlička to represent a population replacement event, and (2) the earliest Aleuts, those predating AD 1000, differ genetically from modern Aleuts. However, if we consider the full data set as a single prehistoric population, mitochondrial differences between the prehistoric group and the modern Aleut population are negligible. The importance of adequate sample sizes to capture temporal changes in genetic frequency data is clear in such studies. These results also emphasize the importance of accurately dating individual samples to be used in ancient DNA analyses.

Acknowledgments We gratefully acknowledge the permissions and support of the Chaluka Corporation, the Aleut Corporation, and the Aleut/Pribilof Island Association. We also thank Greta Hansen, David Hunt, and Douglas Owsley at the Smithsonian Institution for assistance during the collection process. We are grateful to Stephen Ousley for pointing out discrepancies in the population affinities of the samples between Hrdlička's original designations and the accession records of the Smithsonian. We also are pleased to thank Michael Crawford, Dixie West, Doug Veltre, Debbie Corbett, Shawn Carlyle, Elizabeth Marchani, Jacquel Arismendi, and Alan Rogers for advice and intellectual stimulation. Copies of relevant approvals and permissions to conduct this research are available upon request. The research reported here was supported by the National Science Foundation through grants OPP-9974623, OPP-0327641, and BCS-BE 0119759 awarded to D. H. O’Rourke.

Received 27 April 2009; revision accepted for publication 15 June 2009.

\section{Literature Cited}

Aigner, J. S. 1978. The Lithic Remains from Anangula, an 8500-Year-Old Aleut Coastal Village. Tübingen, Germany: Archaeologica Venatoria Institut für Urgeschichte, Universität Tübingen

Aigner, J. S., B. Fullem, D. Veltre et al. 1976. Preliminary reports on remains from Sandy Beach Bay, a 4300-5600 BP Aleut village. Arctic Anthropol. 13:83-90.

Bandelt, H. J., C. Herrnstadt, Y. G. Yao et al. 2003. Identification of Native American founder mtDNAs through the analysis of complete mtDNA sequences: Some caveats. Ann. Hum. Genet. 67:512524.

Black, L. T. 1983. Some problems in interpretation of Aleut prehistory. Arctic Anthropol. 20:49-78.

Black, L. T. 1984. Atka, an Ethnohistory of the Western Aleutians. Alaska History 24. Kingston, Canada: Limestone Press.

Brown, M. D., S. H. Hosseini, A. Torroni et al. 1998. mtDNA haplogroup X: An ancient link between Europe/Western Asia and North America? Am. J. Hum. Genet. 63:1852-1861.

Burch, E. S. 1998. The Iñupiaq Eskimo Nations of Northwest Alaska. Fairbanks: University of Alaska Press. 


\section{4 / SMITH ET AL.}

Cabana, G. S. 2002. A Demographic Simulation Model to Assess Prehistoric Migrations. Ph.D. thesis, Department of Anthropology, University of Michigan.

Cabana, G. S., K. Hunley, and F. A. Kaestle. 2008. Population continuity or replacement? A novel computer simulation approach and its application to the Numic expansion (western Great Basin, USA). Am. J. Phys. Anthropol. 135(4):438-447.

Chou, Q., M. Russell, D. E. Birch et al. 1992. Prevention of pre-PCR mispriming and primer dimerization improves low-copy-number amplifications. Nucleic Acids Res. 20:1717-1723.

Coltrain, J. B., M. G. Hayes, and D. H. O'Rourke. 2006. A radiometric evaluation of Hrdlička's Aleutian replacement hypothesis: Population continuity and morphological change. Curr. Anthropol. 47(3):537-548.

Dumond, D. E. 1987. The Eskimos and Aleuts. New York: Thames and Hudson.

Fitzhugh, W. W., and V. Chaussonnet. 1994. Anthropology of the North Pacific Rim. Washington, DC: Smithsonian Institution Press.

Gilbert, M. T. P., T. Kivisild, B. Grønnow et al. 2008. Paleo-Eskimo mtDNA genome reveals matrilineal discontinuity in Greenland. Science 320:1787-1789.

Handt, O., M. Höss, M. Krings et al. 1994. Ancient DNA: Methodological challenges. Experientia 50:524-529.

Handt, O., M. Krings, R. H. Ward et al. 1996. The retrieval of ancient human DNA sequences. Am. J. Hum. Genet. 59:368-376.

Hayes, M. G. 2002. Paleogenetic Assessments of Human Migration and Population Replacement in North American Arctic Prehistory. Ph.D. dissertation, University of Utah.

Hayes, M. G., J. B. Coltrain, and D. H. O'Rourke. 2003. Mitochondrial analyses of Dorset, Thule, Sadlermiut, and Aleut skeletal samples from the prehistoric North American arctic. In Mummies in a New Millennium: Proceedings of the 4th World Congress on Mummy Studies, N. Lynnerup, C. Andreasen, and J. Berglund, eds. Copenhagen: Danish Polar Center, 125-128.

Hayes, M. G., J. B. Coltrain, and D. H. O'Rourke. 2005. Molecular archaeology of the Dorset, Thule, and Sadlermiut: Ancestor-descendant relationships in eastern North American arctic prehistory. In Contributions to the Study of the Dorset Paleo-Eskimos, P. Sutherland, ed. Mercury Series, Archaeological Paper 167. Hull, Canada: Canadian Museum of Civilization, 11-32.

Helgason, A., G. Pálsson, H. S. Pedersen et al. 2006. mtDNA variation in Inuit populations of Greenland and Canada: Migration history and population structure. Am. J. Phys. Anthropol. 130:123-134.

Hrdlička, A. 1945. The Aleutian and Commander Islands and Their Inhabitants. Philadelphia: Wistar Institute of Anatomy and Biology.

Hummel, S., G. Nordsiek, and B. Herrmann. 1992. Improved efficiency in amplification of ancient DNA and its sequence analysis. Naturwissenschaften 79:359-360.

The International Atlas. 1977. New York: Rand McNally.

Kaestle, F. A., and D. G. Smith. 2001. Ancient mitochondrial DNA evidence for prehistoric population movement: The Numic expansion. Am. J. Phys. Anthropol. 115:1-12.

Keenleyside, A. 1994. Skeletal Evidence of Health and Disease in Pre-and Post-Contact Alaskan Eskimos and Aleuts. Ph.D. dissertation, McMaster University, Hamilton, Canada.

Kolman, C. J., N. Sambuughin, and E. Bermingham. 1996. Mitochondrial DNA analysis of Mongolian populations and implications for the origin of New World founders. Genetics 142:1321-1334.

Krings, M., A. Stone, R. W. Schmitz et al. 1997. Neanderthal DNA sequences and the origin of modern humans. Cell 90:19-30.

Laughlin, W. S. 1963. Eskimos and Aleuts: Their origins and evolution-Physiological and cultural adaptation to facilitate the evolutionary success of Eskimo-Aleut stock. Science 142:633-645.

Laughlin, W. S. 1975. Aleuts: Ecosystem, Holocene history, and Siberian origin. Science 189:507-515

Laughlin, W. S. 1980. Aleuts, Survivors of the Bering Land Bridge. New York: Holt, Rinehart, and Winston.

Laughlin, W. S. 1992. Geographic and temporal variation in Aleuts (Unagan) and prehistory. Unpublished. 
Laughlin, W. S., and J. S. Aigner. 1975. Aleut adaptation and evolution. In Prehistoric Maritime Adaptations of the Circumpolar Zone, W. W. Fitzhugh, ed. Chicago: Mouton, 181-202.

Laughlin, W. S., J. B. Jørgensen, and B. Frøhlich. 1979. Aleuts and Eskimos: Survivors of the Bering land bridge coast. In The First Americans: Origins, Affinities, and Adaptations, W. S. Laughlin and A. B. Harper, eds. New York: Gustav Fischer, 91-104.

Laughlin, W. S., and G. H. Marsh. 1951. A new view of the history of the Aleutians. Arctic 4:75-88.

Lefèvre, C., D. West, and D. G. Corbett. 2001. Archaeological surveys in the Near Islands: Attu Island and Shemya Island. In Archaeology in the Aleut Zone of Alaska: Some Recent Research, D. E. Dumond, ed. University of Oregon Anthropological Papers, no. 58. Eugene: University of Oregon, 251-266.

Marchani, L. E., A. R. Rogers, and D. H. O'Rourke. 2007. The Thule migration: Rejecting population histories using computer simulation. Am. J. Phys. Anthropol. 143(2):281-284.

McCartney, A. P. 1984. Prehistory of the Aleutian region. In Arctic: Handbook of North American Indians, D. Damas, ed. Washington, DC: Smithsonian Institution, v. 5, 119-135.

McCartney, A. P., and C. G. Turner II. 1966. Stratigraphy of the Anangula unifacial core and blade site. Arctic Anthropol. 3:28-40.

Moorrees, C. F. A. 1957. The Aleut Dentition: A Correlative Study of Dental Characteristics in an Eskimoid People. Cambridge, MA: Harvard University Press.

O'Rourke, D. H., R. L. Parr, and S. W. Carlyle. 1999. Molecular genetic variation in prehistoric inhabitants of the eastern Great Basin. In Prehistoric Lifeways in the Great Basin Wetlands: Bioarchaeological Reconstruction and Interpretation, B. E. Hemphill and C. S. Larsen, eds. Salt Lake City: University of Utah Press, 84-102.

Oswalt, W. H. 1967. Alaskan Eskimos. Scranton, PA: Chandler.

Pääbo, S., H. Poinar, D. Serre et al. 2004. Genetic analyses from ancient DNA. Annu. Rev. Genet 38:645-679.

Parr, R. L., S. W. Carlyle, and D. H. O'Rourke. 1996. Ancient DNA analysis of Fremont Amerindians of the Great Salt Lake wetlands. Am. J. Phys. Anthropol. 99:507-518.

Rubicz, R. C., T. G. Schurr, P. L. Babb et al. 2003. Mitochondrial DNA variation and the origins of the Aleuts. Hum. Biol. 75:809-835.

Saillard, J., P. Forster, N. Lynnerup et al. 2000. mtDNA variation among Greenland Eskimos: The edge of the Beringian expansion. Am. J. Hum. Genet. 67:718-726.

Seigel-Causey, D., D. G. Corbett, C. Lefèvre et al. 1995. Report of the Western Aleutian Archaeological Project: Shemya Island Excavations, August 1994. Report on file at the National Geographic Society.

Shields, G. F., A. M. Schmiechen, B. L. Frazier et al. 1993. mtDNA sequences suggest a recent evolutionary divergence for Beringian and northern North American populations. Am. J. Hum. Genet. 53:549-562.

Smith, D. G., R. S. Malhi, J. Eshleman et al. 1999. Distribution of mtDNA haplogroup X among native North Americans. Am. J. Phys. Anthropol. 110:271-284.

Smith, S. E. 2005. A New Perspective on Aleut Genetic History. Master's thesis, University of Utah, Salt Lake City.

StatSoft Inc. 2008. Statistica (Data Analysis Software System), version 8.0. www.statsoft.com.

Stone, A. C., and M. Stoneking. 1993. Ancient DNA from a pre-Columbian Amerindian population. Am. J. Phys. Anthropol. 92:463-471.

Tamm, E., T. Kivisild, M. Reidla et al. 2007. Beringian standstill and spread of Native American founders. PloS One 2(9):e829.

Torroni, A., T. G. Schurr, M. F. Campbell et al. 1993. Asian affinities and continental radiation of the four founding Native American mtDNAs. Am. J. Hum. Genet. 53:563-590.

Turner, C. G., II. 1967. The Dentition of Arctic Peoples. Ph.D. dissertation, University of Wisconsin, Madison.

Turner, C. G., II. 1974. The use of prehistory for direct comparative baselines in the study of Aleut microevolution and adaptation. In International Conference on the Prehistory and Paleoecology 
426 / SMITH ET AL.

of the Western North American Arctic and Subarctic, S. Raymond and P. Schledermann, eds. Calgary, Canada: University of Calgary, 205-215.

Turner, C. G., II. 1991. The Dentition of Arctic Peoples. New York: Garland.

Ward, R. H., B. L. Frazier, K. Dew-Jager et al. 1991. Extensive mitochondrial diversity within a single Amerindian tribe. Proc. Natl. Acad. Sci. USA 88:8720-8724.

West, D., D. G. Corbett, and C. Lefèvre. 1997. NSF Grant Progress Report: The Western Aleutians Archaeological and Paleobiological Project. Report on file at the National Science Foundation.

Woodbury, A. C. 1984. Eskimo and Aleut languages. In Arctic: Handbook of North American Indians, D. Damas, ed. Washington, DC: Smithsonian Institution, v. 5, 49-63.

Wrischnik, L. A., R. G. Higuchi, M. Stoneking et al. 1987. Length mutations in human mitochondrial DNA: Direct sequencing of enzymatically amplified DNA. Nucleic Acids Res. 15:529-542.

Yang, D. Y., B. Eng, J. S. Waye et al. 1998. Technical note: Improved DNA extraction from ancient bones using silica-based spin columns. Am. J. Phys. Anthropol. 105:539-543.

Zlojutro, M., R. Rubicz, E. J. Devor et al. 2006. Genetic structure of the Aleuts and circumpolar populations based on mitochondrial DNA sequences: A synthesis. Am. J. Phys. Anthropol. 129(3):446-464. 